\section{Susana Zanetti}

Susana Zanetti fue Profesora Emérita de la Universidad Nacional de La Plata y Profesora Consulta de la Universidad de Buenos Aires. En ambas casas de estudio ha tenido a su cargo las cátedras de Literatura Latinoamericana I. Además de numerosas compilaciones y artículos en publicaciones académicas, ha publicado: La dorada garra de la lectura. Lectoras y lectores de novela en América Latina (2002), Leer en América Latina (2004). De su labor editorial puede citarse, la dirección de la Historia de la Literatura argentina, 2 ed. 1979-1982 en 5 vols. Ha fallecido en agosto de 2013
Las Memorias de Florian Paucke: Una crónica singular de las misiones jesuitas del Gran Chaco argentino

\title{
LAS MEMORIAS DE FLORIAN PAUCKE: UNA CRÓNICA SINGULAR DE LAS MISIONES JESUITAS DEL GRAN CHACO ARGENTINO
}

\author{
SUSANA ZANETTI \\ Universidad de Buenos Aires \\ Universidad Nacional de la Plata
}

\section{RESUMEN}

El misionero jesuita Florian Paucke (1719-1780) escribió en alemán su extensa crónica sobre los dieciocho años de labor en la reducción de San Javier a su cargo, en el Gran Chaco argentino (al norte de la actual provincia de Santa Fe), interrumpida por la expulsión de la Orden en 1767. Sólo ha sido editada completa traducida al español con el título Hacia allá y para acá. Una estada entre los indios mocobies (1749-1767). De innegable importancia es esta crónica por sus aportes al conocimiento de la cultura mocoví, enriquecida además por las 104 magnificas acuarelas que ilustran la fauna, la flora, la vestimenta, los tatuajes, las comidas, la caza y la pesca, las fiestas religiosas, de la vida cotidiana de los mocoví en la misión.

Palabras clave: Florian Paucke, misiones jesuitas., siglo XVIII, Virreinato del Perú, cultura indígena mocoví.

\section{ABSTRACT}

The Jesuit missionary Florian Paucke (1719-1780) wrote in german its extensive chronicle of the eighteen years of work in the reduction of San Javier to his post, in the Gran Chaco Argentina (to the north of the present Province of Santa Fe), interrupted by the expulsion of the Order in 1767. Only complete edited has been translated into Spanish under the title Hacia allá y para acá. Una estada entre los indios mocobies (1749-1767). This chronicle is of undeniable importance for their contributions to the knowledge of the culture Mocoví, enriched also by the 104 magnificent watercolor paintings that illustrate the fauna, flora, clothing, tattoos, food, hunting and fishing, religious holidays of the everyday life of the Mocoví in the mission.

Keywords: Florian Paucke, Jesuit Missions, Eighteenth Century, Viceroyalty of Peru, Indigenous Culture Mocoví.

Hacia allá y para acá. Una estada entre los indios mocobíes (1749-1767) titula su crónica Florian Paucke. Un acápite o subtítulo en el manuscrito aclara enseguida su experiencia de un desplazamiento que resume, y encierra destacando los sentimientos encontrados con que recuerda su larga permanencia de casi dos décadas en la región del Chaco argentino: Hin und her. Hin süsse und vergnügt, Her bitter und betrübt. Das ist: treu gegebene Nachtricht durch einen im Jabre 1748 aus Europa in WestAmerica, namentlich in die Provinz Paraguay abreisenden und im Jabre 1769 nach Europa zurückkerenden Missionarium, in welcher er 
besonders seinen in der Provinz Gran Chaco unter denen indianern Mocobier, oder so gennanten Guaycuru, achtzebnjabrigen Aufentablt, seine Arbeiten, bennanten Indianer $\mathrm{Hei}$ den und Christen, zurückreise in Europa, wie auch des Landes Witterung, Erdreich, Gewässer, Früchte, Walder, Thiere, Vögel, Fische, kriechende und flügende Ungeziefer, sammt anderen fremden und artigen Beschaffenbeiten erzäblet, mit verschiedenen Kupfern, untermenget, in sechs Theile zergliedert.

Esto es, según la traducción de Edmundo Wernicke:

Hacia allá (fuimos) amenos y alegres, para acá (volvimos) amargados y entristecidos. Noticia fielmente dada por un misionero en su partida desde Europa en el año 1748 hacia la América Occidental, en particular a la provincia del Paraguay y en su retorno a Europa en el año 1769 por la cual él relata especialmente su estada por dieciocho años en la Provincia Gran Chaco entre los Indios Mocobíes o llamados Guaycurúes, su labor, el paganismo y cristianismo de los mencionados Indios; viaje de retorno a Europa como también el clima, terreno, aguas, productos, bosques, animales (cuadrúpedos), aves, peces, sabandijas reptantes y voladoras, junto con otras exóticas y especiales condiciones, intercalada con diversos grabados, dividida en seis partes (Paucke, 1942-1944)1.

En Alemania se habían hecho breves selecciones del texto en 1829, 1870 y 1908, pero solamente en Argentina, la Universidad Nacional de Tucumán publica la primera edición completa en cuatro volúmenes, entre 1942 y $1944^{2}$, traducida por Edmundo Wernicke, con el título Hacia allá y para acá (Una estada entre los indios mocobies. 1749-1767) y con la reproducción de todas las ilustraciones hechas por Paucke, respetando las medidas originales.

Ya anciano revive Paucke en sus memorias ese pasado de vocación de servicio y también de aventura en la conquista espiritual, en el que va postergando referir su expulsión. En la crónica se diseña como un sujeto curioso y cuidadoso en el registro de su experiencia, una experiencia que lo hace sentirse satisfecho y que, en ocasiones, lo lleva a hacer alarde por los riesgos enfrentados, como cuando describe las terribles tempestades que debió arrostrar ya en el primer cruce del océano:

Nosotros estuvimos tan alegres en nuestros ánimos que pensamos poco en los peligros y fatigas pasadas pero yo recordé de algunos cofrades temerosos que dejé en la provincia y en consideración de su índole porcelánea que en muchas circunstancias había notado en ellos, no dudé que hubieran saltado en mil pedazos si hubieran tenido que aguantar con nosotros las tempestades pasadas (Paucke, 1942-1944, I, p. 20).

Si bien se preocupa por aclarar que ha evitado referirse a los muchos peligros vividos en la reducción, como señala al describir al tigre: "Yo tendría mucho que escribir si yo debiera informar de todos los peligros que he pasado entre tigres. Por lo tanto lo omito». (III, $1^{a}$ parte, p. 340 ). No se vanagloria por los logros en la aceptación del cristianismo por los mocoví, ni pone el acento en describir los métodos para alcanzar esa misión. Se detiene, en cambio, mucho más en sus enseñanzas para proporcionar un oficio a los indígenas, como modo de inserción en la sociedad colonial.

El detallado relato nos lleva a preguntarnos si es resultado de su notable memoria. Sólo alguna vez apunta olvidos, como por ejemplo en la descripción del río Paraná cuando se detiene en una especie de loro «del tamaño de un gorrión, igualmente parlanchines y cómicos como los demás. La denominación en lengua mocobí ya se me perdió» (III, 2da parte, p. 316). Es difícil aceptar sin embargo que no haya conservado anotaciones hechas durante su permanencia en la misión, a pesar de que cuando sale expulsado de Buenos Aires en 1767 le secuestraron todas sus pertenencias:

Yo tenía muchos libros que en parte había traído conmigo desde Europa, en parte adquirido en Las Indias o había recibido de regalo por buenos amigos [...]; yo tenía también muchos instrumentos musicales desde Europa como ser violin, Flanta traversa, Mandora, viola d'amor y otros más los que los presentes se repartieron entre ellos; a la par de estos tenía yo mucha herramienta para trabajos de ebanista y escultor. Todo esto junto con aquello que yo tenía de otras cosas como ser instrumentos matemáticos un instrumental entero con el círculo proporcional (¿compás?) que por si sólo costó seis ducados en Ausburgo y era completamente dorado, todo me fue quitado y en mi
Nuestro recibimiento. (dos leguas antes de llegar a la ciudad de Córdoba) (p. 31)

1

Citamos por la edición de la Universidad de Tucumán (19421944, 4 vols.). Se aclara siempre el tomo y la página.

2

Indudablemente estas ilustraciones sustentan también su singularidad -una singularidad compartida con Guamán Poma de Ayala, Juan Zapata Inga y Baltasar Jaime Martínez Compañón, entre otros

\footnotetext{
Las Memorias de Florian Paucke: Una crónica singular de las misiones jesuitas del Gran Chaco argentino

SUSANA ZANETTI
} 


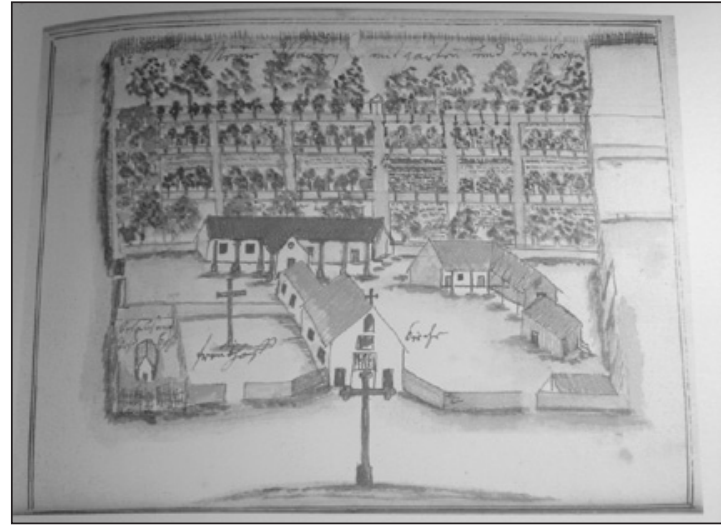

Mi parroquia con huerta y lo de más. A la izquierda: Mi vivienda nueva. Vivienda del cocinero. Cementerio. A la derecha: antigua casa parroquial. Iglesia (65)

3

Del prólogo de Agustín Alzari a Hacia allá y para acá (2010). También con la traducción de Edmundo Wernicke. Texto en CD-Rom y un libro con las ilustraciones del tamaño de los originales.

Las Memorias de Florian Paucke: Una crónica singular de las misiones jesuitas del Gran Chaco argentino

SUSANA ZANETTI presencia secuestrado; sólo me dejaron el crucifijo, un antiguo breviario y dos pequeños libritos eclesiásticos (III, p.83).

Muchas o algunas de ellas pudieron ser hechas en el Chaco como ayuda memoria. Un indicio lo da el ahorro de papel, pues con frecuencia incluyen varios asuntos en una sola ilustración -por ejemplo, dibujos de la carreta, además de la imagen del modo en que los mocoví cruzan el río- y la mayoría de ellas suelen estar dibujadas en papeles pequeños y de igual tamaño. Pensamos entonces que le era difícil disponer de suficiente papel, y que no quería renunciar a reproducir los objetos con todos sus detalles. Las observaciones sobre lo representado en las láminas, especialmente los pormenores sobre el hábitat y las costumbres de los mocoví o de los animales y plantas autóctonos, son apuntadas no sólo en los epígrafes sino también dentro de las acuarelas. Como destaca Agustín Alzari (2010), «el mérito de las pinturas de Paucke radica en la combinación de una técnica escasa con un alto nivel expresivo que continuamente la desborda. [...] Ningún boceto ni libreta auxilió al jesuita en su extraordinaria ambición totalizadora» ${ }^{3}$. Las 104 acuarelas pintadas sobre tela en los 10 rollos de gran tamaño encuadernados con el texto manuscrito de las memorias se encuentran en el monasterio de Zwettl. Allí encontró Guillermo Furlong el manuscrito y la mayoría de las láminas (menos las siete editadas en 1870 por Kobler) e hizo conocer a Paucke en el ámbito hispanoparlante, con su libro Entre los mocobies de Santa Fe, editado en 1938.

\section{Quién es Florian Paucke}

El 24 de septiembre de 1719 nació Paucke en Silesia (actual Polonia), entonces perteneciente a Austria. A los diecisiete años, en 1736, ingresa a la Compañía de Jesús, ya con el pedido expreso de autorización para cumplir su misión en América. Se ordena como sacerdote en 1748, aun debiendo seis meses de cursada. Se le permite para poder realizar su proyecto, pues había recibido la aceptación del Vaticano a fines de 1747, con destino a la provincia Paraquaria, nombre dado por la Orden a la extensa zona, que comprendía la actual república del Paraguay y el norte de la provincia de Santa Fe y el Chaco austral, en el actual territorio argentino. De inmediato inicia el viaje y con él inicia el relato -la travesía por tierras de España y Portugal para embarcarse en Málaga el 20 de septiembre rumbo a Buenos Aires.

Ya al cruzar el territorio español advierte el riesgo de los juicios apresurados y apunta en sus memorias el cuidado que tendrá en el futuro, un modo de asegurar la objetividad de su informe, sustantivo con que define a su texto: "Yo aseguro que escribiré imparcialmente y no apreciaré a ninguno más que a otro. Sigo la marcha de mi relación y hasta aquí no doy preponderancia a ninguna nación hasta que yo haya investigado bien y maduramente en todo» (Paucke, 1942-1944, I, 22).

Después de cuatro meses de navegación llega, a los 29 años, el $1^{\circ}$ de enero de 1749 , con otros misioneros, entre ellos Martin Dobrizhoffer (1967), quien en Historia de los abipones cuenta su labor evangelizadora, realizada en una reducción, como Paucke, en la Provincia Paraquaria. Sobre la naturaleza y los habitantes del Gran Chaco en la etapa considerada por Paucke, se han editado además en español, textos de José Cardiel, Pedro Lozano y José Jolis, también misioneros jesuitas.

Un problema ya resuelto es el apellido: Paucke y no Baucke, como había sostenido en Argentina el padre Guillermo Furlong. Pero la carta firmada por Paucke de 27 de octubre de 1763, existente en el Archivo General de la Nación en Buenos Aires, permitió a Wernicke confirmar el apellido Paucke, ya convencido de que éste no había revisado el manuscrito (hoy perdido), y teniendo en cuenta además el testimonio de Dobrizhoffer, quien en su libro recién mencionado varias veces lo nombra Florianus Paucke.

En el Collegio de los jesuitas reside durante su breve estadía en Buenos Aires, cuya descripción inicia señalando que «es en todo el territorio de Paraquaria la más grande y más notable ciudad, mayor que Praga en Bohemia pero no tan magnífica aunque más ordenada porque las calles son rectas como a cordel» (I, p. 106). Para destacar la hospitalidad que él y sus compañeros reciben, recurre como en muchas otras veces a uno de sus predilectos centros de interés, la comida. La describe con 
mucho detalle y hasta da la receta de lo que los españoles llaman olla podrida (I, pp. 102-104).

Poco después, en la marcha hacia la ciudad de Córdoba en carreta -la dibuja y describe- muestra ya una curiosidad que lo lleva al continuo registro de las singularidades y las extrañas costumbres que encuentra, actitud que sostiene en buena medida el interés de su obra. En el Colegio Máximo de Córdoba permanece cuatro años para terminar sus estudios de teología.

Dieciocho años vive Paucke en América, durante quince de ellos, entre 1752 y 1767, cumple su misión evangelizadora en la reducción de San Javier, fundada a la vera del río de mismo nombre en el norte de la actual provincia de Santa $\mathrm{Fe}$, área sur del Chaco argentino, perteneciente a la provincia jesuita del Paraguay; fue fundada en 1604, atendiendo al pedido de las autoridades coloniales, confiadas en que la dedicación especial de los misioneros sometería a las tribus indómitas, abriéndole así el paso a la posesión de la región, posibilitando también satisfacer la codicia de los colonos en disponer del trabajo de los indios «domesticados».

\section{Paucke y la reducción de San Javier}

El largo relato de Paucke se inserta en el conjunto de cartas y relaciones jesuitas sobre la conquista del Chaco, que se distinguen por el tramado de sus argumentaciones en confrontación con las críticas provenientes de gobernadores u otros grupos de poder coloniales. En diferentes momentos su crónica evidencia que conoce textos jesuitas sobre la conquista y los indígenas nómades cazadores de esa región de frontera, marginal, del virreinato del Perú, lejos también de los otros centros de poder del Río de la Plata, como Buenos Aires o Córdoba. Por ello y dada su cultura y preocupaciones, se entrega a demostrar la importancia de su tarea y valorar especialmente la fauna, la flora, tanto como el territorio y sus habitantes, sin sumarse a la concepción, impuesta sobre todo por Buffon, que presentaba al hombre americano como débil y enfermizo. La crónica de Paucke se integra a la de otros jesuitas destacados, muchos de ellos criollos o españoles con larga residencia en América, respecto del rechazo a las apreciaciones negativas hechas en Europa, como fueron, entre otros ejemplos notables que respondieron a esa desvalorización, concentrándose en el desarrollo de las civilizaciones precolombinas y/o de la conquista, las obras de Francisco Xavier Clavijero, Historia antigua de México (1780-1781); de Juan Ignacio Molina, Historia geográfica, natural y civil del reino de Chile (1782 y1787), o de Juan de Velasco, Historia del Reino de Quito en la América Meridional (1789).

Sabemos que las crónicas jesuitas difieren según sea la distancia temporal y espacial entre el momento de la escritura y el de la experiencia en América, sobre todo por la incidencia de la expulsión que intensifica la necesidad de demostrar el éxito de la evangelización. El texto de Paucke es un muy buen ejemplo, especialmente cuando reparamos en que su historia familiar y el pasado personal, las referencias a su tierra o a los sucesos posteriores a los años americanos, prácticamente están ausentes en el relato, concentrado solamente en ese hin del título de sus memorias. Desde ese «allá» regresa a su tierra, radicándose dos años más tarde en el convento cisterciense de Zwettl, en Baja Austria, cuyas autoridades le solicitan que escriba la crónica. Con la disolución de la orden en 1773 pasa a vivir en Bohemia hasta su muerte hacia 1780.

En los dos primeros capítulos de la segunda parte de su crónica, Paucke se retrotrae a los comienzos de San Javier en 1743, siguiendo el relato de su fundador, Francisco Burges, quien lo recibirá más tarde al llegar a la reducción. Volver a estos inicios, le permite referir la importancia de ella, pues logró durante su permanencia el asentamiento de los mocoví y también en buena medida puso freno a los frecuentes asaltos a la ciudad de Santa Fe y al arreo de ganado de los campos circundantes. Las fuerzas militares apoyaron la fundación, dado que ellas no habían podido impedir las incursiones de los indígenas, que rápidamente se internaban en la selva, su medio natural, que les aseguraba protección y alimento.

Los textos coloniales españoles coinciden en condenar los rasgos culturales de estos grupos nómades, recolectores y cazadores, cuya enorme destreza para la guerra no pudo evitar la expansión española de la frontera tucumano-chaqueña a comienzos del siglo XVIII, y la consiguiente mutilación del territorio étni-
Ensalada de un misionero (cebollas silvestres, ajo silvestre, cardo, rábano silvestre, pimienta silvestre, pimientos, ají, otra pimienta española.

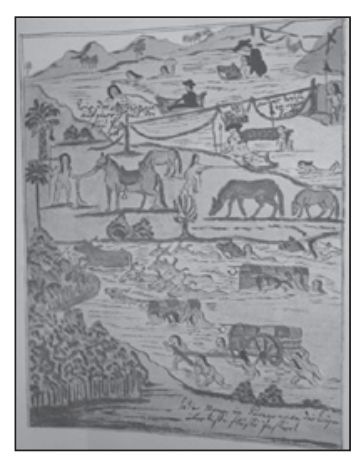

De qué modo el misionero sobre un cuero pasa el rio. Otra manera en cesta de viaje. De qué modo se pasan en Paracuaria los carros por ríos hondos.

\footnotetext{
Las Memorias de Florian Paucke: Una crónica singular de las misiones jesuitas del Gran Chaco argentino

SUSANA ZANETTI
} 
co original. Ese avance los fue desplazando y constriñendo, arrinconándolos en las zonas inundables, en un estrecho territorio en que los conflictos interétnicos y la necesidad de mejorar los recursos de supervivencia los obligaba a una continua movilidad, que hacía difícil su pacificación y control mediante los poblamientos estables proyectados por los jesuitas.

Carlos D. Paz (2003) señala que no se ha estudiado bien hasta ahora esa imagen de simples cazadores-recolectores, pues falta describir y analizar las adaptaciones de estos grupos, que le permitieron subsistir ante los avances de los indios vecinos y de los «conquistadores» blancos, españoles y portugueses.

Los diversos grupos del área practicaban una agricultura basada en la tala y quema; aprovechando luego el desmonte, sembraban maíz, melones, zapallos, etc. El texto y las ilustraciones de Hacia allá y para acá muestra los numerosos recursos vegetales (rábanos, cebollas, ajos, hongos, frutales, entre otros) y animales (tigres, liebres, conejos, avestruces, nutrias, gran variedad de aves y peces, etc.) de que disponían durante la estación seca. Vale la pena citar esta detallada enumeración, típica de Paucke, de la riquísima fauna de una isla del río Paraná:

En esta ínsula se encontraban muchos tigres, ciervos, puercos monteses, avestruces, venados, leopardos, monos, zorros grandes y chicos; lobos marinos y puercos marinos (carpinchos) en gran cantidad. Esto era muy conveniente y agradable a los indios; también Cithaalin comenzó a sonreírse, y especialmente cuando él vio el campo llano hacia el costado oeste, donde al lado de lagos (llenos de) juncos se encontraba justamente una gran cantidad de todos estos animales junto con muchos miles de caballos silvestres, que en esta tierra selvática pacían a veces de a trescientos, ochocientos, también a mil (II, p. 41).

Los robos de ganado sucedían durante la temporada de lluvias, en verano, desde noviembre a marzo, cuando las inundaciones provocaban la desaparición de los animales silvestres -las liebres, conejos, vizcachas, etc.y de los vegetales (maíz, melones, zapallo, etc.), que las lluvias impedían sembrar. El ganado cimarrón había resuelto hasta entonces las carencias, pero cuando comienza a extinguirse en el XVIII recrudece el conflicto con los indios, que empezarán a apoderarse del ganado criado en las haciendas, que habían ocupado las tierras libres de inundaciones. Paucke describe y dibuja esos vegetales y animales que constituían la dieta básica del indio, contribuyendo a desmentir la falsa imagen del indio bruto y ocioso. También describe e ilustra el papel que el cuero tenía en los objetos de la vida cotidiana, como comprueba ya al inicio de su asentamiento en la misión: «Mi vivienda y [...] la iglesia no tenían paredes sino que estaban rodeadas por cueros frescos de buey pero el techo de la iglesia era de paja y el techo de mi vivienda era también de cuero crudo» (I, 169).

Estos rasgos de la relación entre españoles e indígenas, tuvieron derivaciones cuando ya estaba instalada la reducción. Por una parte, según el relato de Paucke explica, pidió con gusto al destacamento militar el deseo de los indios de alejar la reducción y acercarla más a la selva. Los motivos del pedido son no sólo porque la cercanía de los españoles daba malos ejemplos y maltrato a los indígenas, sino también por las inundaciones, porque los terrenos malsanos para el ganado, y muy especialmente además porque:

las estancias de los españoles estaban tan cerca que el ganado podía mezclarse en una media noche con el ganado de los españoles, en cuya ocasión los españoles buscaban el consumo más entre el ganado de la reducción que entre el propio, como demostraba la experiencia diaria (II, p. 39).

Desde su llegada a la reducción Paucke se dedica a enseñar a los indígenas diversas prácticas culturales europeas, poniendo el acento en oficios que propendieran la sedentarización de los mocoví, ayudaran a su mantenimiento y les facilitaran la incorporación a la sociedad española, una tarea que cumplían las distintas órdenes religiosas, de «domesticar» al nativo. Lutier y buen compositor, Paucke enseñó música y organizó talleres de herrería, zapatería, carpintería y fábricas de ladrillo, velas, jabón o pan.

El reconocimiento de la pacificación que conseguían las misiones, no diluía el rechazo español de un control que impedía el aprovechamiento indiscriminado y el maltrato del indígena; colaboraba en cambio en acentuar las rivalidades con las misiones establecidas por la cada vez más influyente y rica Compañía de Jesús. En 1765 comienzan las persecuciones de españoles y portugueses, crecen 
en 1766, hasta obedecer el decreto de Carlos III de expulsión de sus dominios de Europa y América, del $1^{\circ}$ de abril de 1767. Unos 2600 jesuitas, la mayoría nativos de América, recibieron plazos perentorios para dejar su lugar de residencia. La expulsión ya había sido decretada en Portugal en 1759 y en Francia cinco años más tarde, en 1764.

Ya camino al destierro Florian Paucke se pregunta «¿Cuál fue el motivo? No lo conocían ni ellos ni nosotros» (III, $1^{\circ}$ parte, p. 99). Inicia así uno de sus comentarios sobre la expulsión, a sabiendas de que está llegando al final de su defensa del buen gobierno jesuita en las misiones, que con su crónica busca legitimar. Sin embargo, al expresar sus quejas deja traslucir las causas. Lo hace por ejemplo en este fragmento, donde hace valer sus servicios y los beneficios que los indígenas han dado a la corona:

Yo no quiero detenerme más en un mayor relato de los servicios que los indios han prestado al Rey y su país, son suficientes estas pruebas para que se extermine la conspiración que en la Corte se había producido contra las misiones y se reconozca claramente cuán vano ha sido el rumor que los Jesuitas con sus indios trataban de cercar los españoles para destruirlos finalmente (II, p. 314).

El valor de su misión lo mostraban los riesgos constantes que enfrentaba al contrariar los intereses del gobierno de españoles o portugueses, que justificaban la explotación del trabajo indígena negando la inteligencia y la capacidad de los indios para el aprendizaje. Paucke reconoce, en cambio, en distintos fragmentos de su relato la capacidad creativa y la inteligencia de los indígenas, pensamiento que se inscribe en la corriente renovadora de la Compañía de Jesús en el siglo XVIII ${ }^{4}$. Cuando destaca los conocimientos y las condiciones físicas y morales exigidos a los misioneros jesuitas enviados a América puntualiza:

Tal vez se cree que un misionero de Indias no precisa otra cosa que realizar una buena doctrina cristiana porque se considera a los indios unas gentes incapaces y de ningún modo inteligentes. ¡No! Se necesita algo más pues los incapaces pueden dar buenos bocados a mascar tanto en lo que concierne a la ciencia y la virtud del maestro, como también a la paciencia y mansedumbre (del mismo) (III, p. 141).

En el segundo tomo, cuando utiliza el cuestionario, a la pregunta sobre la inteligen- cia indígena responde: «Ellos tienen un entendimiento tan bueno como todos nosotros, pero él no es tan agudo porque ellos viven sin doctrina ni ocasión que podría hacer agudo su entendimiento» (II, p. 259) y más adelante comenta: «Al principio en el descubrimiento y la conquista estos países no fueron considerados gentes sino animales y así se condujeron los Españoles para con ellos pues los viajeros les echaron sobre los hombros la carga» (II, p. 281), para agregar luego que los indios fueron aceptados por la Orden «como niños de tutela y mediante muchas prescripciones reales, mandamientos y decretos fueron libertados de semejante esclavitud» (II, p. 282).

Paucke deja traslucir los problemas con el gobierno colonial de Santa Fe, con «los españoles» como los llama, pero es sólo hacia el final de la crónica, cuando cobran mayor protagonismo las hostilidades y rivalidades con la Compañía de Jesús, sufridas a lo largo de diez años, encara abiertamente las acusaciones de que la Orden pretendía hacer de Paraquaria un reino propio. Por último, el gobernador de Buenos Aires cumpliendo la orden real de expulsión, a la llegada de los jesuitas a la ciudad, dispone la prisión de los jesuitas hasta ser embarcados, en tanto el texto insiste en apuntar el dolor de los numerosos indios de su misión que lo acompañaban y el «alboroto» en la ciudad («todo fue pleno clamor llorar y lamentarse; otros maldecían de tal proceder para con los Jesuitas y compadecían íntimamente nuestro destino» (III, p. 71). Los habitantes lo colmaban de vituallas para el viaje, que Paucke no se priva de memorar: «chorizos largos secados al aire, y aun otros gruesos cuartos de chancho, no secados a la manera de jamones en la chimenea sino al aire» (III, p. 90).

\section{Los problemas lingüísticos}

Si bien escribió en alemán y conocemos su crónica en traducción al español, el texto de Paucke ha ingresado al repertorio de fuentes coloniales argentinas, porque nos introduce de otro modo en los problemas de la otredad y la heterogeneidad, en los cuales sin cesar estamos implicados: La singular extranjería de Paucke nos advierte sobre las mediatizaciones particularmente complejas que solicitan en general estos textos, siempre ligados a los condicionamientos culturales, lingüísticos,
Véase Darko Sustersic, "Corrientes internas en la Compañía de Jesús durante el siglo XVIII a la luz de los testimonios de tres polémicas» en Bartolomeu Meliá, (ed.) (2002) Historia inacabada futuro incierto. VIII Jornadas internas sobre las misiones jesuitas, Asunción, Centro de Estudios Paraguayos.

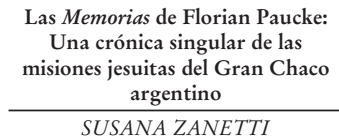


ideológicos, etc., que establece la cultura y los intereses del cronista.

Entre españoles, criollos, mestizos e indígenas Paucke es otro. Perfila otras distancias al dar cuenta de la sociedad heterogénea en el área sur del virreinato del Perú, en la cual circulaban otros extranjeros, en una población de españoles, criollos, grupos sometidos y por someter, junto a una variada trama de subalternidades -mestizos, esclavos, moros y africanos, etc.

Es diferente por no ser español, y por lo tanto no estar comprometido en defender la legalidad del imperio, concentrando su habilidad en la defensa de la reducción ante el comandante español de las tropas de la zona. Los españoles son una imagen de la otredad, por la vestimenta o comida, así los describe y los pinta. Pero sobre todo son otros por su conducta, su moral y codicia. Paucke articula un nosotros bastante diverso por sus inclusiones y exclusiones, aparentemente desentendido de los problemas entre españoles recién llegados, los de ya larga residencia o los criollos -una única vez se refiere a los «gachupines», y traduce el vocablo como «extranjeros».

Pero es otro por su lengua. Porque escribió en alemán pero con expresiones peculiares que indican que ha hablado otro idioma siendo niño y que dificultan la comprensión. Pesa en este asunto el hecho de que no se cuenta con el manuscrito original sino con una copia que, considerada atentamente, muestra que Paucke había dictado el texto y no revisó con cuidado su transcripción. Las ediciones alemanas, siempre fragmentarias, no resuelven estas dificultades pues presentan transcripciones libres y modernizadas.

Y sobre todo es otro porque ingresa a una formación social que vive una situación comunicativa lingüística y cultural muy diferente a la propia. Donde además, debe aprender el lenguaje de los sectores dominantes, el español de los colonizadores, para cumplir una experiencia compleja de plurilingüismo y por ende, de pluralidad cultural. Fundamenta la verdad de su crónica pues aclara que sólo cuenta en ella lo observado y vivido en la misión de San Javier y en los viajes hechos por obligaciones de su tarea en ella, y que puede hacerlo porque ha superado la barrera lingüística: «Mi mayor preocupación fue aprender el idioma para que yo no necesitara hablar por señas con los indios como un mudo» (I, p. 170).
Cuenta después de su llegada, cuando ya ha interactuado en el mundo colonial en las ciudades de Buenos Aires y Córdoba, sus dificultades para aprender español («En cuántas ocasiones las lágrimas se me cayeron de los ojos y me invadió una profunda tristeza que la lengua no quiso pegárseme tan pronto como yo pretendía», (II, p. 49)). Este problema se multiplica al enfrentar el aprendizaje del mocoví y el contacto con la gran variedad de lenguas indígenas habladas en el ámbito de la reducción. Dedica varios capítulos a la lengua y a los rasgos gramaticales, sintácticos y lexicales peculiares.

Una y otra vez repite su deseo de «Ser perito en el idioma», narra sus estrategias para lograrlo, reproduce sus conversaciones con indígenas e inserta frases en sus lenguas, que por una parte revelan sobreimpresiones de experiencias en la memoria y acercamientos entre enunciado y enunciación; y por otra, ponen en escena las tensiones entre las exigencias de argumentar y los sentimientos ante el recuerdo de lo vivido.

Cree, afirma en el Prefacio de su obra, que estos conocimientos le han permitido narrar lo vivido con «sincera verdad» $\mathrm{y}$, sin generalizar, porque entiende los riesgos de disolver la diversidad que intenta respetar su etnocentrismo en el espacio ( Yo admito que las inclinaciones, usos y costumbres, no sean iguales en todo el mundo", (I, p. 22)), y en el tiempo («a cuya mutabilidad están sujetos todos los hombres y países», (I, p. 4)).

En toda la crónica llama la atención la búsqueda de la exactitud en el detalle, reforzada por las ilustraciones, de diferentes aspectos de la cultura mocoví, pero suele comentar sus dificultades. En un momento, al referirse a la lengua, evidencia sus límites de comprensión de la otredad, pues aunque rehúya homogeneizar sus experiencias concretas, su afán por resaltar la labor misionera en las reducciones, lo hace desdecirse. La cita siguiente apela a la comparación con lo animal, de la que suele valerse, y aquí también a la demonización, un recurso prácticamente ausente en él. Beatriz Vitar (2003) señala que en el Chaco no había religiones propiamente dichas sino «supersticiones» y que Paucke no condena por ello a los indios, en cambio dirige sus sermones contra los brujos -importantes focos de poder- y amenaza con perseguirlos hasta su destrucción: 
Se encuentran entre ellos unas lenguas tan confusas e incomprensibles que el misionero sin la real ayuda de Dios pudiera aprenderlas casi imposiblemente. Apenas si se entiende una sílaba o una letra de ellas cuando conversan y uno cree que solo fuere un graznido de gansos o de otros animales. En frecuentes veces yo he hecho presente a mis indios que a mí no me parecía otra cosa sino que el Enemigo Malo fuere el maestro de todos sus idiomas para que su dificultad detuviere los misioneros y con ella si bien no impidiera la salvación de sus almas la hiciere a lo menos muy dificultosa (II, p. 171).

\section{Las experiencias entre los mocoví}

Emblemáticamente monumentaliza los obstáculos para llegar y abandonar América con el cruce del Atlántico, asediado por tormentas largamente descriptas, que se suceden multiplicadas cuando debe vadear ríos crecidos por las inundaciones, o cuando enfrenta los peligros desconocidos de la naturaleza americana, aunque sus dibujos ilustran mucho más la curiosidad y el placer del viajero ante lo nuevo -basta ver el dibujo de los «tigres», como llama a los yaguaretés, descansando tranquilos, simpáticos, fácilmente amigables. Entretanto, es el texto el encargado de subrayar los esfuerzos y riesgos de evangelización para pacificar una zona en continua lucha entre los distintos grupos indígenas, sin presentarlos como feroces y extremadamente belicosos. En el primer capítulo de la Tercera parte, dedicada a explicar «La manera de vivir, usos y costumbres de los indios americanos en el paganismo", luego de aclarar que sólo puede referirse a su experiencia y a los que "yo mismo he observado durante el tiempo de mis años de misión» y que lo expondrá con la modalidad del cuestionario. " $i$ Los indios son pues, hombres como nosotros?» Es la primera pregunta, cuya respuesta afirmativa involucra el aspecto físico y espiritual, destacando la fuerza, el hábil manejo de las armas, la inteligencia del indio, y también muy brevemente, su vida familiar y su organización social.

De algunos de ellos cuenta con detenimiento su pertenencia grupal, su carácter y costumbres, así como el modo que van comprendiendo los valores culturales que se les quiere imponer, como ocurre con $\mathrm{Ne}-$ vedagnac. Lo describe minuciosamente con admiración en el capítulo «Primera visita por el cacique Nevedagnac», sólo a él dedicado.
«Este cacique me gustó cordialmente; según mi conocimiento fisionómico el fue uno de los mejores que yo había conocido. Yo me empeñé en recibirlo con la mayor amabilidad y el se me presentó con admirable cortesía» (II, p. 77).

Para lograr la obediencia de los caciques, Aletin es la figura ejemplar del respeto y la amistad que Paucke ha logrado con ellos, en tanto va consiguiendo mucho más difícilmente una buena relación con Cithaalin, Alangain y Nevedagnac. Aletin y Cithaalin, dos figuras de valor paradigmático, en un principio contrapuestas, el primero en tanto prototipo del rebelde apegado a su cultura, discutidor y razonador, pero incapaz de dominar sus pasiones, frente al segundo, ejemplar por lo empeñoso, sensato y obediente: sobre esta base articula el proceso que va dando como resultado la cristianización y la imposición de los nuevos modos civilizatorios, fundados en los discursos, en el relato de conductas ejemplificadoras, y sobre todo en la disposición para la vida comunitaria de los jesuitas. Solamente una vez cuenta una «milagrosa incitación al bautismo» en la abuela de Cithaalin, que pide ser bautizada momentos antes de su inesperada muerte -episodio que sirve además para corroborar que no imponen autoritariamente los ritos religiosos.

Los episodios que jalonan la progresiva aceptación de la vida en la reducción del cacique Cithaalin van explicando los métodos para lograr la pacificación: su acercamiento a la reducción, cómo establece las bases de las tratativas para incorporarse, si bien aún apegado a sus costumbres, en tanto insiste Paucke en mostrarle los beneficios sociales y espirituales de aceptar la fe cristiana -el bautismo, así como las concepciones religiosas y éticas de los misioneros, uno de cuyos momentos es el ejemplo de su abuela, recién citado-. Culmina este proceso ejemplar cuando Cithaalin acompaña a los misioneros llorando apenado un buen trecho del camino hacia el puerto de Buenos Aires, para cumplir la orden de expulsión.

Todavía seguirá presente Cithaalin en la tercera parte, «De la manera de vivir, usos y costumbres de los indios americanos en el paganismo», en la que, con el sistema de preguntas y respuestas, y también de los catecismos y otros textos destinados a la evangelización, da cuenta de la cultura mocoví. Parte de la descripción y las imágenes físicas, para en-

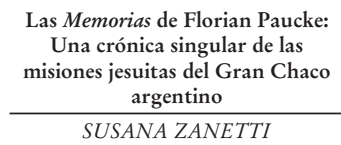


seguida explicar los tatuajes y otros adornos corporales (aceptados muy lentamente por los misioneros), pasando luego a las armas, la alimentación, el lenguaje, etc.

Aquí se perfilan más nítidamente los esfuerzos por compenetrarse de la cultura mocoví, aunque registra sus intentos desde los comienzos mediante el acercamiento a través de lo que se comparte, como en este ejemplo en el que ridiculiza la pretendida superioridad de su cultura, cuando se encamina a San Javier:

Mientras tanto yo estaba en la orilla despejada en el agua y lodo; tronaba y granizaba sobre mí; la violenta y continua lluvia me había remojado tanto que yo temblaba por todos los miembros: Mi pequeño indio [...] estaba desnudo delante de mí y para que la lluvia no le mojara tanto la cabeza desnuda se colocó [...] mi sombrero clerical y se paró ante mí como si me solicitara contemplarlo y observar si esta gala no sería sentadora también para él. Esta monería me movió a reírme y me alentó cuando vi que mi pequeño desnudo camarada indio comenzaba todavía a divertirse porque yo, el arropado, tiritaba de frío» (I, p. 165).

Innumerables secuencias narran confrontaciones culturales a través de interacciones muy diversas, desde compartir la caza de monos (II, cap. VIII) hasta la difícil aceptación de la comida del otro, rechazada con asco («Yo hice un gran esfuerzo en mandar asar carne de salvagina recién muerta, sin ser lavada y llena de sangre y comerla pero para causar un placer», (II, 62)). La extrañará más tarde, ya de vuelta en su tierra: «yo me había acostumbrado ya tanto a ese comistrajo que lo he saboreado con mayor agrado que un asado preparado conforme al arte. Debo confesar (otros me llamen o no un tragaldabas) que después que yo he retornado de las Indias, he sentido antojos más por un asado indio preparado de semejante manera que por una pierna de ternero preparada en óptima forma» (II, 182); defenderá además su valor alimenticio, para concluir, como tantas otras veces, dando la receta del «asado con cuero», tradicional en la pampa argentina, ofreciendo la del asado indígena al lector:

Yo recuerdo de cierta cura que los señores médicos suelen ordenar a aquellos que abrigan en su cuerpo una naturaleza viscosa y húmeda y humores perniciosos. Es la cura por el asado que yo he visto usar mucho en las ciudades indianas. Yo aseguro que les hará mejores efectos que un asado a la parrilla o un asado zapatero o semejantes que se suelen presentar en las mesas más distinguidas pues lo que el asado en sí pudiera tener de bueno, lo echan a perder los hierros de cocina, condimentos añadidos y especies que no son poco nocivas al hombre en su salud» (II, p. 182).

Cito además el cierre del episodio comentado: «iQuién tuviera un apetito [...] de semejante asadito, se presente ante mí; yo conozco especialmente bien la receta y -si con ello se hace un servicio- quiero prepararle también el asado» (II, pp. 182-183).

Paucke coincide con otras crónicas jesuitas sobre el Chaco en representar a los indígenas sin freno para excesos que destruyen las relaciones entre los mocoví, arriesgando además el entendimiento con otros grupos. Relata e ilustra las borracheras que culminan en violencia, tanto como la voracidad con la carne vacuna, evidenciando la necesidad y los límites del control que busca la reducción, si bien la crónica no escatima narrar la pasión por la comida del narrador:

Recién habían reunido trescientas cabezas de ganado y arreado a pastar en el campo aledaño. Ahí comenzó el tragar. Eran más o menos unas dieciocho familias de indios, calculada una familia en nueve almas; había que darles de comer bastante. Dentro de tres días se carnearon seis reses vacunas para todos, pero parecía que los indios no se contentaban con tan poco ... y se quejaban por padecer hambre aunque fuera de esto mataban muchos tigres, avestruces, ciervos y semejantes para su sustento (II, p. 20).

Tal preocupación, muchas veces reiterada, funciona como reaseguro de sus argumentaciones ante las luchas por el dominio de los indígenas sometidos. Pero justamente esta cuestión colabora en impedirle evadir concepciones homogeneizadoras del otro, evidentes en sus estrategias para obtener del indígena la aceptación de la tutela, acudiendo a procedimientos contradictorios. De continuo muestra la disuasión mediante el razonamiento o el consejo, y al mismo tiempo refiere cómo busca favorecer la enseñanza valiéndose de tretas destinadas a sujetos pensados como si fueran niños - «estos Mocobíes, mis niños» (II, p. 81). Las citas sobre estos procedimientos, tomadas del mismo fragmento, permiten 
advertir el continuo vaivén entre una y otra actitud:

Finalmente no es de admirar que un indio se apegue tan cándidamente a sus prejuicios tan mal concebidos cuando en Europa muchas ideas semejantes, aun más salvajes, se encuentran en cabezas al parecer razonables. Los indios no deben ser inculpados tanto porque su incapacidad los disculpa. Pero tales gentes malévolas son mensajeros de Satanás que quieren substraer de la buena enseñanza de sus sacerdotes a los indios inclinados al mal e ignorantes. Todo parece ser puro interés de los pobres e ingenuos indios (II, p. 23).

Poco antes había escrito:

Aletin demostró un gran placer por estos preparativos y aunque el indio es el hombre más haragán en el mundo ni ha aprendido la menor cosa de un trabajo, es sin embargo apto de imitar lo que ve. Para invenciones y cosas especulativas se encuentran en América pocos indios selváticos que tuvieran habilidad, ¿ 0 es que son tal vez demasiado inconstantes en su fantasía o pensamiento? (II, p. 19).

Corroboraba con ello la acción de las misiones jesuitas no sólo respecto de la evangelización, sino en lograr la pacificación y en dotar a los indígenas de una educación que les permitirían sobrevivir en la sociedad española. Al persistir en el relato la representación de los mocoví como reacios a la vida sedentaria y al trabajo, puede Paucke mostrar cómo esa antigua condición era el soporte de los logros civilizatorios de los misioneros ante el fracaso español. Esto significaba la aceptación de las normas de la sociedad colonial, en las cuales el trabajo era la condición para cubrir las necesidades de subsistencia, y también para el pago del tributo que se solventaría con los cultivos, los trabajos en cuero y los tejidos de los indígenas. Para aumentar los ingresos Paucke averigua, aprende y luego enseña cómo se hacen las velas y el jabón, más tarde agrega el aprendizaje de carpintería («Hicimos puertas, marcos de ventanas, mesas y cosas semejantes» (II, p. 52), construye un torno y un horno de ladrillos e ilustra la fabricación de vasijas, monturas y estribos, y a la vez de penachos y flechas.

Estas explicaciones sobre la economía de la misión, da pie a la aclaración del sentido de la explotación de la yerba mate -cuya comercialización descansaba en la red organi- zada por los colegios jesuitas-y desmentir las acusaciones de enriquecimiento, pues sólo se había encontrado en ella la posibilidad de proporcionar una bebida, un «té», que con cierto éxito frenaba los desmanes de las borracheras. A su vez justifica la cadena de estancias jesuitas con numerosas cabezas de ganado vacuno y ovino, pues se las destinaba a paliar la voracidad mocoví y el robo de ganado.

El tratamiento y el espacio concedido a las comidas muestran el placer de Paucke por la buena mesa, aun en situaciones difíciles, por ejemplo cuando recién disipada una tempestad, anota la receta del gazpacho, ocasión además para comentar sus cualidades de cocinero que, como sus habilidades manuales, caracterizan sus actividades en la misión desde temprano: mientras otros jesuitas y el padre Burges se dedicaban a enseñar a leer e instruir en la doctrina cristiana, Paucke se ocupaba de trabajos menos prestigiosos, que serán siempre los suyos en América: «[...] como yo no era aún del todo perito en el idioma, (me pidió que) me encargara de los asuntos caseros y campestres, también hiciera de maestro de cocina, maestro de graneros y guarda mayor de bosques» (II, p. 100).

Los saberes de nuestro cronista comprenden también el arte de curar, que exhibe en ocasión de la epidemia de viruelas de 1759, con la emulsión que utilizaba como remedio:

Era una sustancia de diversas semillas de melones de agua (sandías) y otros melones machacados en conjunto [...] otras semillas de pepino, semillas de zapallos dulces [...]. Estas semillas todas machacadas en conjunto $y$ coladas con agua por un pañito rinden una leche preciosa; ésta con más agua y endulzada con azúcar le daba a mis enfermos a beberla con ahínco: pero pera bebida ordinaria (les daba) agua de cebada; para hacer brotar las viruelas agua de lentejas (III, p. 37).

Pero sobre todas sus competencias prevalece su afición musical, a la que una y otra vez vuelve para contar el aprendizaje de los indígenas, la formación de una pequeña orquesta con su coro, cuya renombre provoca la invitación a tocar en las procesiones y otras fiestas religiosas, para la evangelización y para la interacción con nuevas formas de sociabilidad y del uso del ocio, como otra manera de consolidar las nuevas sociedades americanas. Sus dibujos detallan con orgullo la suntuosidad de esas celebraciones, haciendo siempre espacio al placer de la comida.

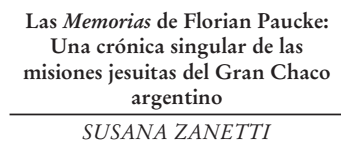


El orgullo por su competencia para aprender y enseñar, y sobre todo por sus logros de inducir el trabajo, constituye una de sus estrategias discursivas para poner de relevancia la eficacia social de la organización misionera. Esta preocupación, muchas veces reiterada, funciona como reaseguro de sus argumentaciones ante las luchas por el dominio de los indígenas sometidos. Pero justamente esta cuestión colabora en impedirle evadir concepciones homogeneizadoras del otro, evidentes en sus estrategias para obtener del indígena la aceptación de la tutela, acudiendo a procedimientos contradictorios. De continuo muestra la disuasión mediante el razonamiento o el consejo, y al mismo tiempo refiere cómo busca favorecer la enseñanza valiéndose de tretas destinadas a sujetos pensados como si fueran niños - «estos Mocobíes, mis niños» (II, p. 81). Las citas sobre estos procedimientos, tomadas del mismo fragmento, permiten advertir el continuo vaivén entre una y otra actitud:

Si el misionero sabe algo, si él es hábil y dispuesto a semejantes cosas, ellos aprenderán cuanto ven; si él no lo es, permanecen ellos unos posmas pues ¿̇de cuál otro podrían ellos aprender? Los Españoles mismos son poco empeñados a aprender algo de un arte, todo está en el comercio. Ellos consideran como el ejercicio más despreciable el ejercer un oficio manual. No se encontrará un Español indiano que fuere un sastre, zapatero, carpintero o semejante; todos estos oficios y otros más son únicamente ocupaciones de los esclavos y mulatos (II, p. 279).

Hacia allá y para acá, ya el título privilegia el desplazamiento designando un relato de viaje centrado en el nuevo mundo americano. Describir, informar, la tarea obligada del cronista, es respetada por Paucke tanto cuando describe la flora y la fauna del ámbito natural, como cuando se detiene en las ciudades -edificios, trajes y costumbres de sus habitantes-, si bien estos intereses no desvían el ocuparse de las instituciones religiosas, que ha visitado muchas veces con sus indios músicos para actuar en iglesias y conventos. Pero sobre todo, le interesan los modos nativos de resolver las necesidades y problemas, y así describe y dibuja la construcción y el uso de la carreta, como ya dijimos, o de una especie de bolsa de cuero con la que los indios cruzan los ríos, o se detiene en la destreza para arrojar las boleadoras o detalla a los jinetes que pescan cabalgando de pie sobre el recado cuando las crecidas del Río de la Plata indican abundancia de peces. Paucke se circunscribe a la experiencia inmediata, ayudado por sus habilidades de artesano.

Hacia allá y para acá, dos espacios separados por el tiempo y la distancia; dos culturas, diferentes formas de vida, de costumbres y creencias que vuelven a unirse para Paucke en la escritura. Él Chaco argentino es lo que la escritura refiere, el allá, que vuelve al convento de Zwellt, el espacio donde escribe, desde donde lo recuerda y que evidentemente añora. Enmarcan el relato los desplazamientos de la ida y el regreso por territorio europeo, para enfrascarse enseguida de esos pasajes en las cosas extrañas y buenas (fremden und artigen dice el texto, si traducimos con las acepciones más inmediatas, más comunes) de la experiencia vivida en el allá por la cultura del sujeto. Cuando el texto relata la vida en la reducción, muy pocas veces se vuelve hacia el espacio propio del narrador, sólo permanece en los paradigmas culturales que dirigen su mirada y sus juicios.

Convivir en la reducción bajo la obediencia de los jesuitas, constituye la garantía de la labor evangelizadora. Este es el horizonte en que actúa Paucke; entraña aculturaciones impuestas por sus concepciones culturales que dejan escasos resquicios para permanencias propias de los mocoví, como demuestra su crónica. Los caciques mencionados ocupan el primer plano de la dicotomía entre los indígenas mansos y aculturados en oposición a los grupos no sometidos, los guaycurúes (los toba, entre otros). Paucke no dedica espacio a las deserciones, salvo a la muy breve de $\mathrm{Ci}^{-}$ thaalin (casi enseguida se incorpora), que debieron ser seguramente muchas, si tenemos en cuenta la información de Enrique Palavicino en su Breve noticia sobre los mocovíes actuales, donde dice que luego de la expulsión, las misiones caen en decadencia, los indios vuelven a los bosques y treinta años más tarde San Javier no existe. Hecho que puede mostrar un modo de resistencia cultural y asimismo dar cuenta de las limitaciones de la comprensión de Paucke acerca de la interacción cultural que describe.

\section{Bibliografía}

Cardiel, José (1930), Diario del viaje del R.P. José Cardiel, Buenos Aires, Facultad de Filosofía y Letras. 
Dobrizhoffer, Martin (1967), (De abiponibus), Historia de los abipones, Santa Fe, Universidad Nacional de Litoral, 3 vols.

Furlong, Guillermo (1939), Entre los vilelas de Salta, Buenos Aires, Academia Literaria del Plata.

Jolis, José (1972), Ensayo sobre la historia natural del Gran Chaco, Santa Fe, Colmegna.

Lozano, Pedro (1941), Descripción corográfica del Gran Chaco Gualamba, Tucumán, Universidad Nacional de Tucumán.

Mandrini, Raúl J. y Carlos D. Paz (2003), Las fronteras hispanocriollas del mundo indigena latinoamericano en los siglos XVIII$X I X$, Neuquén, Limay.

Meliá, Bartolomeu (ed.) (2002), Historia inacabada, futuro incierto, VIII Jornadas internas sobre las misiones jesuitas, Asunción, Centro de Estudios Paraguayos.

Paucke, Florian (1942-1944), Hacia allá y para acá. Una estada entre los indios mocobies (1749-1767), Tucumán, Universidad Nacional de Tucumán.

Paz, Carlos D. (2003), "'como es su costumbre hacer casi cada año’ Algunas con- sideraciones sobre las actividades de los pueblos del Gran Chaco» en Mandrini, Raúl J. y Carlos D. Paz (2003), Las fronteras hispanocriollas del mundo indígena latinoamericano en los siglos XVIII-XIX, Neuquén, Limay.

Pino, Fermín del y Carlos Lozano (coords.) (1995), Visión de los otros y visión de sí mismos, Madrid, CSIC.

Vitar, Beatriz (1988), Tucumán y el Chaco en el siglo XVIII. Milicias, jesuitas y fronteras, Madrid, Universidad Complutense.

Vitar, Beatriz (1999), «El lenguaje de la conquista. La visión de los pueblos chaqueños en el «discurso» jesuita del siglo XVIII» en Carmen Perrilli (comp.) (1999), Las colonias del Nuevo Mundo. Discursos imperiales, Tucumán, Instituto Interdisciplinario de Estudios Latinoamericanos, Universidad Nacional de Tucumán, 2 ed., pp. 245-254.

Fecha de recepción: 02/03/2013

Fecha de aceptación: 29/07/2013
Las Memorias de Florian Paucke: Una crónica singular de las misiones jesuitas del Gran Chaco argentino

SUSANA ZANETTI 
